\title{
The Food Safety Regulations Infiltrate the Thinking and Practice of the Cold Food Teaching in the Course of Health and Diet Therapy
}

\author{
Yu-Chen HAN ${ }^{1, a}$, Yun-Sheng JIANG ${ }^{2, b^{*}}$, Zi-Bin SHI ${ }^{1, \mathrm{c}}$ and Qin-Yi ZHOU ${ }^{1, \mathrm{~d}}$ \\ ${ }^{1}$ Collaborative Innovation Center of Foodology Studies, Chongqing Business Vocational \\ College, Chongqing 401331
}

${ }^{2}$ College of Tourism and Cuisine, Yangzhou University, Yangzhou, Jiangsu 225127

ahanyuchen1991@126.com, bjysqd62@163.com, ${ }^{\mathrm{C}} 270059898 @ q q . c o m$, d389525023@qq.com

${ }^{*}$ Corresponding author

Keywords: Cold dishes, food safety risks, food safety regulations, product standards, responsible persons

\begin{abstract}
Starting with the 'People's Republic of China Food Safety Law' that was issued and implemented in 2009, combining the actual situation of the 'Cooking Practice' curriculum in the 'Health and Diet Therapy' course, we analyzed the latent food safety risks in the processing and operation of various types of cold dishes, and elaborated The knowledge system to control these risks, the laws, norms, standards, and inspection methods that should be followed. This article also shows the basic methods for establishing new recipes and new techniques for cold dishes with a low degree of risk, aiming to make cooking practitioners have a clear responsibility for food safety awareness.
\end{abstract}

\section{Introduction}

College education in Chinese culinary relative majors has so far established over 30 years. In the initial stage of the professional construction, 'Chinese Cuisine Research', a culinary magazine, has founded at that period. There is a famous column called 'Culinary Philosophy and Law'. It shows that there are legal concepts in the culinary studies.

The status of the 'People's Republic of China Food Safety Law' (here in after referred to as the 'Food Safety Law') promulgated and implemented in 2009 cannot be shaken over the plenty laws that relate to culinary. As the saying goes, food is priority of people, and safety is the first priority of food. As a category of food business units, the catering industry must carry out processing and sales activities within the legal framework of food safety [1].

In the production and operation of the catering industry, cold dishes are served on the table at first. Cold dishes have become high-risk food products encountering food safety accidents such as food poisoning and food-borne diseases [2].

The 'Health and Diet Therapy' course requires the extensive use of cold dishes and cooking techniques with high food safety risks such as cold mixture and low temperature operation. Therefore, it is extremely necessary to infiltrate the concept of food safety in teaching. We combine our own teaching experiences to analyze the relevant courses of 'Health and Diet Therapy' and the specific implementation of the safety regulations education for the practical operation of cold dishes. We hope to seek more suggestions from fellows. 


\section{Legal Requirements for Food Safety}

The fight between humans and diseases is eternal. The implementation of full quality control from farm to table has become a global task in the field of food safety. Cooking as a terminal operation of the food chain plays a decisive role in preventing illness from entering the mouth and ensuring consumers' safety [3].

Under the background of governing the country according to law, a culinary major college student who is about to become a talent in catering management or practical operation, he or she should understand the food safety relevant rules that are closely related to the catering industry. These rules, as a whole, include laws, regulations, and national standards, as well as government-related notices, local standards, and local regulations.

Laws relating to the catering industry or food and beverage include 'Food Safety Law of the People's Republic of China', 'Regulations on the Implementation of Food Safety Law of the People's Republic of China' and 'Law of the People's Republic of China on the Quality and Safety of Agricultural Products' [4].

The relevant management regulations include the 'Measures for the Administration of Food and Beverage Service Licenses', 'Food Safety Operational Codes for Foodservice', 'Administrative Regulations for Foodstuff Purchasing for Foodservice Purchasing for Foodstuffs', 'Detailed Rules for the Implementation of Public Health Management Regulations', and 'Foodservice inspection agencies', 'Regulations on Management', 'Food Safety Supervision and Management Regulations for Catering Services', 'Food Safety Supervision and Management Regulations for Major Event Catering Services', 'National Food Service Safety and Education Outline for Food Safety (2011-2015)', 'Emergency Public Health Emergency Regulations'[5].

Relevant national standards include the Food Safety Management System Catering Industry Requirements (GB/T 27306-2008), Food and Beverage Disinfection Sanitation Standards (GB 14934-1994), Food Safety National Standards Disinfectant (GB 14930.2-2012), Product Catering Processing Specification (GB/T 23498-2009) and so on.

The government notices and local standards and regulations related to the catering industry, such as the implementation plan of 'lean meat essence' special rectification program for catering services, the urgent notification on the prevention of 'race oil' inflows into catering services, and the surface hygiene requirements for ready-to-eat foods in the catering industry (DB31/410-2008), Salad Hygiene Standards (DB31195-2007) and others.

These laws and regulations are closely related to hygiene management in food processing in the food and beverage industry. In the practical teaching of cooking, lists of laws and regulations should be listed. On the one hand, it is convenient for students to expand their studies after class. On the other hand, from a processing session of cold dishes, teachers can arrange students to write thesis to improve the effectiveness of research teaching [6].

\section{The Cold Dishes Safety Risk and Control Status}

Cold dishes have divided into two categories: raw and cooked food. Their processing flow can be successively summarized as: raw material receiving $\rightarrow$ storage $\rightarrow$ primary processing $\rightarrow$ knife cutting processing $\rightarrow$ raw cold dishes, or raw material receiving $\rightarrow$ storage $\rightarrow$ primary processing $\rightarrow$ heating cooking $\rightarrow$ cold storage $\rightarrow$ knife-cutting processing $\rightarrow$ cooked cold dishes [7]. The former one includes sashimi, raw shrimp slices, squid, crabs, sea bream, and fruit and vegetable salads. The latter includes white pheasants, bacon, brine shrimp, and marinated mushrooms. Some assorted platters have both. 
Food safety risks are divided into biological and chemical risks. Biological risks include bacteria and their toxins, viruses, parasites, and pest factors. Chemical risks include intentionally added chemical food additives, agricultural chemicals, prohibited substances, and cleaning compounds [8].

Taking sashimi as an example, the biological risks are mainly bacteria and parasites. Bacterial risk and fish species, origin (clean water source aquaculture), low-temperature preservation conditions of processed fish, operation to reduce pollution during primary processing, quasi-sterilized operation during knife processing, preservation of ice before serving, pre-consumer sterilization Seasoning and other factors related to the allocation. There are different microbial floras between different water resources. In the ocean, there are risks such as Vibrio parahaemolyticus, Vibrio cholerae, Vibrio alginolyticus, Anisakis nematophila, etc.. When it comes to freshwater fishes, the unsafe bacteria spieces are mainly Aeromonas and Neisseria. In order to control the risks, marine fishes such as salmon come from other places and rely on cold preservation and antibacterial protection. If repeated thawing, it will cause more bacterial growth. If the operation of the knife-cutting operation that removes the intestine and maggot tissue from the primary processing is not standardized, it will cause new pollutions. The fish fillets are related to the disinfection of knives, plates, hands, plates, and rice dumplings. The requirements for sterilizing operations also include the disinfection of air. In order to avoid these link pollutions, it is necessary to establish a no-bacterial pollution-free operation procedure similar to a surgical operating room. Before serving, servicers are supposed to use sterile water to make ice and control the temperature and time of preservation. Besides, suggestions on the amount and time of use of bactericidal seasonings should be provided. It is also advisable to include suggestions that the consumption time should not exceed half an hour. The relevant regulations cover seafood products. Food and Beverage Processing Practices (GB/T 23498-2009), Fish Hygiene Standards, Food Safety Standards, Microbiological Testing of Vibrio parahaemolyticus, Drinking Water Hygiene Standards, etc.[9].

Taking crystal meat as another example, its chemical risk is mainly the amount of sodium nitrite used as a coloring agent and its residual amount. The meat is made from pork and marinated with sodium nitrate. The cooked meat products are made by special processing. The finished products are served after cutting and serving. Although sodium nitrite is approved for use by the state, it is limited in scope of use. Excessive use can cause acute poisoning and cause death. In order to make sodium nitrite evenly distributed in the meat and avoid exceeding the standard, it should be prepared with water into a dilute solution and then marinated. This is a key technology. It is important to infiltrate, inject or tumble this nitrite into large pieces of meat evenly so as not to cause bacterial spoilage caused by impregnation. Relating to meat and meat processing, relevant regulations include hygiene standards for cooked meat products, nitrites for food additives, and hygiene management methods for food additives have been published. In addition, the discharge of wastewater with nitrate should also meet the environmental protection requirements [10].

Taking fruit and vegetable salads as the last example, the risks include biological risks and chemical risks too. Salad as a raw food, its processing without heating process, the kitchen commonly used condiments; there are fewer varieties with strong bactericidal effect, resulting in the current low level of compliance of food safety supervision [11-14]. In the processing step, the increase of blanching, vinegar stain, acidification, and fermentation of raw materials will reduce the detection rate of pathogenic bacteria. To increase the pre-sterilization of 
condiments used (such as hot oil), the use of alkaline water and disinfectants in the raw material cleaning process is an effective means to control bacteria. The standards and methods for the use of detergents and disinfectants for fruits and vegetables, and hygienic standards for condiments are involved here. Its chemical risk is related to the pollution and residues of pesticides and chemical fertilizers. The establishment of a pollution-free agricultural product supply base is effective, which is related to the pollution-free agricultural product standards, their quality and safety law. The quality inspection should be strengthened against salad hygiene standards (DB31195-2007).

It can be seen that the processing of food and beverage cold dishes varies according to the type of food as well as the risks involved in food safety vary. The laws and regulations involved are relatively wide. It could not be sufficient to solve the specific issues that simply relying on the general hygiene regulations of food companies or the canteen food hygiene system.

\section{The Construction of Cold Vegetable Processing Specifications, Product Standards and Inspection Systems}

There are many kinds of cold dishes. For example, there are dozens of kinds of fruit and vegetable salads with characteristic flavors as well as more than 200 kinds of Chinese-style fruit and vegetable salad dishes, fruit and vegetable soups, and home-made sauces. At present, issues include non-standard formulas, the ambiguous amount of raw materials, the sanitary conditions in the processing links, poor or uneven sanitary conditions, no bacteria-control conditions and unawareness of storage or shelf life. In this regard, we believe that the following issues must be resolved:

First of all, a cold vegetable processing specification should be established. In China, the food safety operation regulation has required to equip a specific place to process the cold dishes. This is the basis of the operation of cold dishes. But for the management of the catering industry, various types of other requirements should also be met, including the use of bacterial fence factors and methods for specific items. Generally, more efforts need to be made by food safety experts individually [15].

Second, food safety standards for cold dishes should be built up. In China, some local standards have been in public. In the future, they will be gradually expanded to all foods in the menu. Therefore, the establishment of corporate standards is more appropriate for. With the standards, the evaluation of the supervisory organization is more supportive. For the enterprises, their self-managements are also more standardized [16].

In addition, a product inspection system is eager to show up. Establishing an online rapid test method for finished products of cold dishes, semi-finished products during the production process, and accident foods is an urgent matter. At present, there have been several methods such as rapid bacterial count, acidity insertion assay, pathogenicity immunoassay qualitative test, induction thermometer, etc., which can be used for reference. The test equipment is required to easy to operate. The measurement is time-saving, and the cost is low. Specific studies should be conducted to continuously improve the level of industry technology and equipment [17].

In this process, students can also be encouraged to enter the training room, spend summer vocation to do social activities, and write the graduation thesis through personally investigating the applied formulas and literatures. They can formulate the basic formula, measure the health indicators, construct the barrier factor, and determine the improved formula and comparing the advanced nature of new technologies [18]. For excellent works, 
teachers can recommend this type of skills and various technical competitions or publish those papers to expand the influence.

\section{Cold Dishes Processing Business Should Assume Responsibility for Food Safety}

In teaching activities, in addition to carefully teaching how to do it, it is also necessary to strengthen the sense of responsibility of the university students and to take responsibility for the food processing behaviors they are engaged in.

Food business operators shall engage in production and business activities in accordance with laws and regulations and food safety standards. They shall be responsible to the society and the public, ensure food safety, accept social supervision, and assume social responsibilities.

In the food safety responsibilities assumed by the catering service industry, the legal person is the first responsible person. He or she should take food and beverage safety as his or her own responsibility. First-line processing personnel, as directly responsible persons, shall bear corresponding legal responsibilities.

The Food Safety Law stipulates administrative liability, economic responsibility, and criminal responsibility for violations of the law. In addition to receiving administrative penalties, the violation of the 'Food Safety Law' constitutes a crime, including the crime of illegal business, production and sales of food crimes that do not meet the safety standards, production and sale of toxic and harmful food crimes, will be handed over to the judicial department to handle the case and sentence. In addition to this, it is also necessary to bear the civil liability for damages in accordance with the provisions of civil law.

In the instructional design, students can be arranged to collect materials according to relevant key words such as 'chef', 'legal responsibility', 'sentence', 'food safety accident', etc.. Through that, they are able to learn to how to analyze the causes of food safety accidents and reinforce their awareness of law-abiding by the interactive learning through the one-person case. They also can cultivate a correct attitude of rigorous scientific work which make them a new generation of people who are law-abiding and highly responsible.

\section{Summary}

Food safety is the foundation of health and nutrition. We analyze the food safety risks of various types of cold dishes and reveal the laws, norms, standards, and testing methods that should be followed to control various types of cold food. What's more, we propose the establishment of a new recipe, a new process, and a basic method for the construction of cold dishes with a low degree of risk. This article has built a new standards of cold dish processing, food safety standards and inspection systems up. Its aims to strengthen students' awareness of law-abiding concepts and cultivate a new generation of culinary talents who know and understand law.

\section{References}

[1] Nan Junhua. Food safety control in catering industry [M], Beijing, China Standard Press, 2005, 5-6.

[2] Zhou Jingli. The People Take He Shi as the Day: A Survey of China's Food Safety Status [M], Beijing, China Workers Press, 2007, 3-7. 
[3] Chen Xiwen, Deng Nan. Research on China's food safety strategy [M], Beijing, Chemical Industry Press, 2004, 938-940.

[4] Wu Jing, Qian Feng. Catering industry standards and regulations [M], Beijing, China Light Industry Press, 2013, 1-3

[5] Wang Longxing. Food safety is in your hands (for catering industry executives) [M], Shanghai, Shanghai Science and Technology Press, 2008, 3-5.

[6] Hu Xiaoya. Selection of research teaching cases [M], Nanjing, Jiangsu Education Press, 2012, 10-16.

[7] Zhu Yunlong. Chinese cold plate technology [M], Beijing, China Light Industry Press, 2008, 12-13.

[8] Tian Huiguang. Key technologies for food safety control [M], Beijing, Science Press, 2004, 299-231

[9] Cui Zhumei.Study on Health of Sashimi [J].Culinary Journal of Yangzhou University, 2001, 18 (3): 22-25

[10]Wang Zhijun. Catering food safety [M], Beijing, Higher Education Press, 2010, 33.

[11]Guo Yuqin, Li Xiaoling. Investigation of sanitary conditions in salad processing [J]. Chinese Journal of Hygienic Engineering, 2001, 10(4):153-154.

[12]Lana Chung, Seo-Jin Chung.Comparing the liking for Korean style salad dressings and beverages between US and Korean consumers: Effects of sensory and non-sensory factors [J]. Food Quality and Preference, 2012, 26(1): 105-118.

[13]Wang Libin, Dai Changfang. Application of HACCP in Microbiological Control of Cold-free Vegetables [J]. South China Journal of Preventive Medicine, 2004, 30(3):47-50.

[14]Chun Yun. Special Hygienic Requirements for Salad Dishes [J]. Food Science, 1995(4):23-24.

[15]Jingjing Zhu,Tao Ren. Analysis and Control of Flora in Vegetarian Salad [J]. Journal of food engineering and technology.2012, 1(11):28-37.

[16]Dong Jie, Xu Wei, Zhu Jingjing, Yuan Yang. Analysis and Control of Bacterial Flora in Composed India Vegetable Salad [J]. Journal of Food Engineering and Technology, 2013, 2(1): 69-76.

[17] Wu X. Analysis and control of sweet bell pepper bacterial fermentation [J]. Technological Innovation and Application, 2013 (22): 5-6.

[18]Shen Yan, Zhu Jingjing, Liu Xi, et al. Study on the health quality control of potato lettuce rolls [J]. Journal of Cooking at Yangzhou University, 2013, 30(4):26-30. 